\title{
Los medios en campaña o el amotinamiento de los electores: Perú, elecciones presidenciales 2006
}

\author{
Santiago Pedraglio* (Universidad de Lima, Perú) \\ Con la colaboración de Ana Vílchez \\ Recibido 7/8/2007 \\ Aprobado 25/9/2007
}

RESUMEN: Este artículo es una reflexión-investigación sobre el comportamiento de los medios de comunicación peruanos durante las elecciones presidenciales del 2006, y gira en torno a los encuentros y desencuentros entre estos, los candidatos presidenciales y los electores. El objetivo es analizar el comportamiento de los medios durante los últimos meses de la primera vuelta electoral y, a la vez, explicar su actuación y la de los candidatos con el fin de acercarse a los espacios de construcción de las opiniones políticas ciudadanas.

Palabras clave: Procesos electorales - agenda electoral - cobertura mediática partidos políticos - candidatos

\section{The media in campaign or the rise of the voters: Peru, presidential elections 2006}

SUMMARY: This is an opinion and research article about the media behavior in the Peruvian presidential elections of 2006; it revolves around the agreements and disagreements between the media, the candidates and the voters. The article's main goal is to analyze media behavior during the last months of the electoral first round; at the same time, it explains the media and candidates performance in order to get close to the place were the citizen political opinions are build.

Key words: Election process - election agenda - media cover - political parties candidates

* El autor agradece a Iana Málaga sus aportes a la versión final de este texto. 
Imposible hablar de victoria de la comunicación sin hablar de aquel a quien se dirige: el receptor. En realidad, el receptor lo complica todo, rara vez está donde se le espera, a menudo comprende algo distinto de lo que se le dice y de lo que se desearía que comprenda por el sonido, la imagen, el texto o el dato. Es la caja negra.

Dominique Wolton. Salvemos la comunicación. Aldea global y cultura. Una defensa de los ideales democráticos y la cohabitación mundial).

\section{Introducción}

T as elecciones generales del 2006, L convocadas para elegir al Presidente de la República y a los parlamentarios nacionales, se iniciaron formalmente el 15 de enero, con la inscripción de las planchas presidenciales - presidente y dos vicepresidentes por lista - y concluyeron la primera semana de junio con la elección del nuevo mandatario, en una segunda vuelta electoral.

Con la primera vuelta (9 de abril) quedaron elegidos los congresistas y definidos los candidatos presidenciales que se debían enfrentar en una segunda vuelta, por haber alcanzado las dos primeras mayorías relativas pero sin obtener más del $50 \%$ de los votos válidos: Ollanta Humala, del Partido Nacionalista, y Alan García, del Apra.
Como se sabe, en el ballotage triunfó el candidato del partido aprista, que alcanzó cerca de $52 \%$ de la votación contra $47 \%$ del otro candidato.

El análisis que se presenta a continuación gira en torno a los encuentros y desencuentros de tres actores centrales del proceso electoral: los medios de comunicación, los candidatos presidenciales -en muy pocas oportunidades acompañados de sus partidos políticos - y los electores, ciudadanos que se nutren de diferentes tradiciones y puntos de vista políticos, sociales y culturales. En cuanto al ámbito temporal, se reduce a la primera vuelta electoral, pues consideramos que refleja mejor la cobertura mediática global al involucrar a todos los candidatos presidenciales (20). ${ }^{1}$ Las referencias a la segunda vuelta tienen un carácter puntual y secundario.

En la primera sección se presenta un resumen de las prioridades de los medios al informar sobre el periodo observado del mencionado proceso electoral. En la segunda sección se comentan las relaciones entre los medios de comunicación, los candidatos y los receptores, a propósito de la cobertura mediática observada.

El primer objetivo de este artículo es presentar y analizar el comporta-

1 Aunque nos referiremos a lo consignado en la prensa sobre los candidatos que finalmente obtendrían las cinco más altas votaciones: Ollanta Humala (30\%), Alan García (24\%), Lourdes Flores (23\%), Martha Chávez (7\%) y Valentín Paniagua (5\%); es decir, los que acumularon cerca del $90 \%$ del total de los votos válidamente emitidos. 
miento de los medios de comunicación durante los últimos meses de la primera vuelta de la campaña electoral del 2006, a partir de tres subtemas: a) cómo se distribuyó y privilegió la cobertura mediática entre los candidatos presidenciales, sobre todo entre los tres principales; $b$ ) cuál fue, en ese mismo periodo, la agenda electoral de los medios; y c) qué perfil diseñaron los medios sobre los más importantes postulantes presidenciales. El segundo objetivo es desarrollar una explicación preliminar sobre la actuación de los candidatos de cara a los medios de comunicación, y acercarse a un reconocimiento de los espacios de construcción de las opiniones políticas ciudadanas en tiempos electorales.

La información utilizada tiene como fuente principal el monitoreo de medios efectuado por la Asociación Civil Transparencia, como parte del Proyecto de Observatorio Regional, que comprendió el seguimiento de la prensa escrita del 10 de enero al 9 de abril del 2006 -últimos tres meses de campaña electoral correspondiente a la primera vuelta -, y de la televisión y la radio del 10 de febrero al 9 de abril -últimos dos meses de esa misma campaña-. ${ }^{2}$

\section{Los medios, los candidatos y los electores: Confrontación, diálogo $y$ negociaciones}

\section{La agenda electoral de los medios}

Para monitorear la agenda electoral de los medios de comunicación se distinguieron dos ámbitos centrales: los "sucesos de campaña" y los "planes de gobierno". ${ }^{3}$ Los medios de comunicación nacionales se concentraron en difundir información vinculada a los "sucesos de campaña". La cobertura sobre los "planes de gobierno" de los candidatos presidenciales fue claramente menor.

En este contexto, entre los medios monitoreados de alcance nacional, la radio, seguida por la televisión, es el medio que más espacio brindó a la información sobre planes de gobierno (véase el gráfico 1). El dato resulta sorpresivo en tanto se suele considerar que la prensa escrita se vincula más a la reflexión y a la presentación del contexto político y social, mientras que la radio y la televisión son percibidas como medios que hacen un uso sistemático de la espectacularización de la noticia, y, sobre todo, en el caso de la radio, sujeta a la inmediatez.

2 Para mayor información sobre este monitoreo, véanse los boletines Observatorio Regional y Datos Electorales, que Transparencia publicó desde enero hasta agosto del 2006, cuya versión electrónica está disponible en la página web de la institución (www.transparencia. org.pe), así como la base de datos de la institución.

3 La categoría "sucesos de campaña" agrupa las opiniones (declaraciones de los candidatos y sobre ellos, referidas a sus tendencias políticas, impresiones personales, calificaciones, 


\section{Gráfico 1 \\ Cobertura temática por tipo de medios de comunicación (porcentajes)}

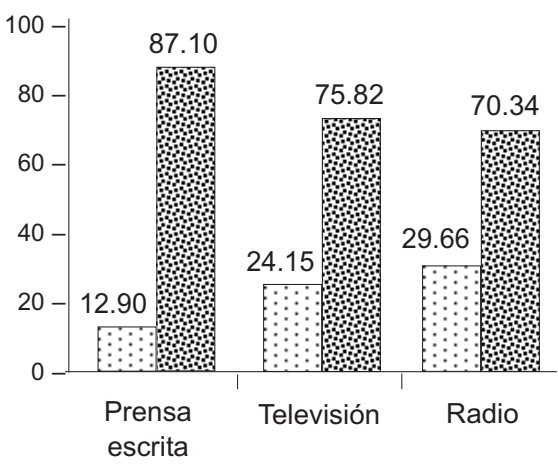

$\therefore$ Planes de gobierno

9.8 Sucesos de campaña

Fuente: Base de datos del monitoreo de medios de la Asociación Civil Transparencia. Elaboración propia.

Cuando se analiza con mayor precisión el conjunto de la información brindada por los tres tipos de medios, se ve que el interés se concentró en los "sucesos de campaña", sobre todo en aquellos vinculados a las opiniones de los candidatos y a las denuncias o acusaciones de unos candidatos contra otros. En todos los medios, el tema "candidatos" recibió la mayor cober- tura: $42 \%$ en la prensa escrita, $41 \%$ en la televisión y $38 \%$ en la radio. Le siguen las noticias o informes relacionados con la organización partidaria (sobre todo las elecciones internas y los problemas dentro de cada agrupamiento), el proceso electoral (información proveniente de los organismos electorales) y la difusión de los resultados de las encuestas.

En cuanto a la cobertura sobre los planes de gobierno, en la prensa escrita el mayor número de referencias se ligó al empleo. Este interés - no olvidar que solo es relativo - es coherente: el Perú tiene una estructura del empleo muy deficiente; cabe mencionar, por ejemplo, que más del $50 \%$ de la población económicamente activa está en situación de subempleo. En segundo término, se trató el tema "democracia y Estado de derecho"; y en tercero, la política económica, estrechamente ligada al empleo pero también al crecimiento sostenido y la distribución de los ingresos.

En esta área - los planes de gobierno-, la televisión desplegó una cobertura similar a la de la prensa escrita: de los cuatro primeros temas más difundidos por este medio, coinciden en

simpatías, etcétera), información sobre elecciones internas (acusaciones, denuncias y descargos, encuestas electorales, actividades de campaña, organización y capacitación electoral, resoluciones y normatividad electoral, hojas de vida y sociedad civil). El conglomerado "planes de gobierno" agrupa las propuestas u opiniones de los candidatos sobre políticas de Estado: derechos humanos, reforma del Estado, política exterior, salud, educación, comercio exterior, sostenibilidad fiscal, desarrollo rural, entre otros (Observatorio Regional 3, 27 de febrero del 2006, p. 1). 
tres (empleo, política económica y democracia y Estado de derecho). No obstante, la televisión se ocupó más de la educación, aspecto en el cual la mayoría de los candidatos presidenciales pusieron un especial énfasis. Es interesante, también en este caso, que un tema aparentemente menos mediático, como la educación, obtuviera una cobertura más amplia en la televisión que en la prensa escrita.

Como se señaló, la radio superó el porcentaje total de información referida a los planes de gobierno, frente a la televisión y la prensa escrita. La radio otorgó a la educación la cobertura más alta (como en la televisión); el segundo lugar correspondió a la infraestructura; y al igual que en los otros medios, el empleo fue también uno de los tres temas más tratados.

\section{Los candidatos y las agrupaciones políticas}

Este acápite muestra la cobertura mediática que obtuvieron los candidatos presidenciales más votados. A modo de introducción, el gráfico 2 muestra la cobertura que recibieron las agrupaciones políticas en general, es decir, no solo el candidato presidencial, sino también los aspirantes a congresistas y los voceros partidarios.

En bloque, es decir, como agrupaciones políticas, el Partido Aprista obtuvo la mayor cobertura global, seguido de Unidad Nacional. Unión por el Perú y el Partido Nacionalista, alianza que sostuvo la candidatura de Ollanta Humala, merecieron el tercer lugar como cobertura global, pero en la televisión obtuvieron una cobertura

\section{Gráfico 2}

Cobertura a las agrupaciones políticas (porcentajes)

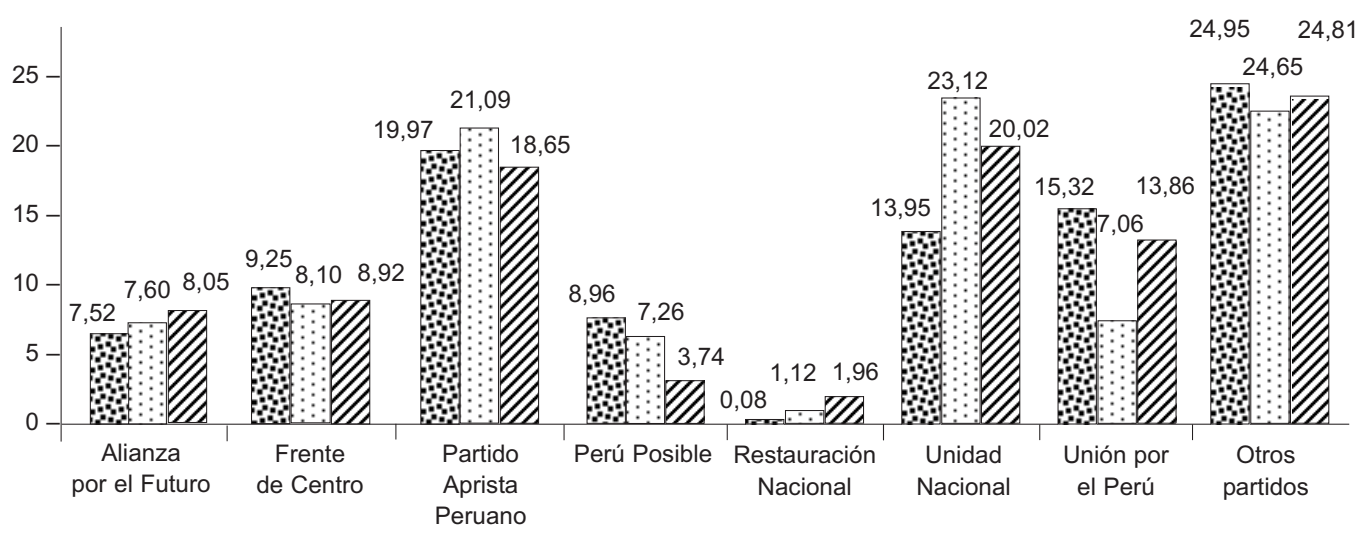

\section{ㄱensa escrita $\quad$ : Televisión $\mathbb{Z}$ Radio}

Fuente: Base de datos del monitoreo de medios de la Asociación Civil Transparencia.

Elaboración propia. 
bastante menor, incluso más reducida que la de agrupaciones políticas que finalmente ocuparían el cuarto, quinto y sexto lugar en la primera vuelta: Alianza para el Futuro (Martha Chávez), Frente de Centro (Valentín Paniagua) y Restauración Nacional (Humberto Lay), respectivamente.

Centrándose en los seis candidatos que obtuvieron las más altas votaciones en la primera vuelta, se constata que, como tales, la dimensión de la cobertura favoreció a Lourdes Flores y en segundo término a Alan García. Solamente en la radio, Humala superó a García (véase gráfico 3). Cabe anotar que más del $50 \%$ de la cobertura de la prensa escrita y de la televisión estuvo destinada a los tres candidatos que obtendrían las más altas votaciones (Humala, García y Flores); la radio, en cambio, les dispensó algo menos del $50 \%$.

Sin embargo, si se compara la cobertura total obtenida por los seis principales candidatos en la prensa escrita, con la que toma como fuente directa de su información al propio candidato, ${ }^{4}$ se constata una importante diferencia (véase el gráfico 4). La distinción per-

\section{Gráfico 3}

Cobertura a los candidatos presidenciales como fuente directa (porcentajes)

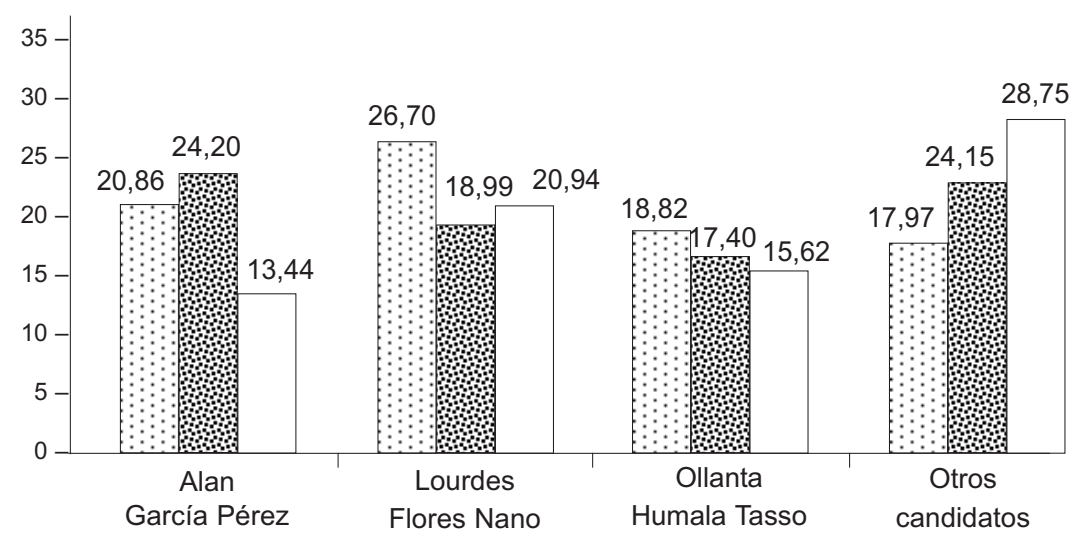

Prensa escrita $\quad$ 羿 Televisión $\quad \square$ Radio

Fuente: Base de datos del monitoreo de medios de la Asociación Civil Transparencia. Elaboración propia.

4 Es decir, el medio de comunicación pudo hablar o informar sobre determinado candidato, pero no necesariamente lo tomó como fuente directa de la información. 
mite observar, por ejemplo, que sobre Ollanta Humala los medios escritos opinaron o informaron en una medida importante, pero comparativamente sobre todo frente a Lourdes Flores y Alan García - se le tomó mucho menos en cuenta como fuente directa de la información.

Lourdes Flores se configuró como fuente directa de la noticia en bastantes más oportunidades que el candidato del Partido Nacionalista, lo mismo que Alan García, Valentín Paniagua, Humberto Lay y los otros candidatos, siempre en comparación con la información que no los implica como fuente directa. Martha Chávez, la candidata del fujimorismo, resultó tam- bién menos consultada o tomada como fuente.

Las implicancias de esta diferencia tienen que ver con la posibilidad de que se reproduzca o no la información comunicada por el candidato. No necesariamente significa que la noticia lo esté favoreciendo, pero sí que se está transmitiendo algo que él ha generado. En este sentido, el escaso porcentaje con que la prensa escrita tomó a Ollanta Humala y a Martha Chávez como fuentes de la información publicada sobre ellos, indica que sus posibilidades de comunicar su punto de vista fueron proporcionalmente más reducidas que las de los otros candidatos.

\section{Gráfico 4}

Prensa escrita: el candidato mencionado en la información versus el candidato como fuente directa (porcentajes)

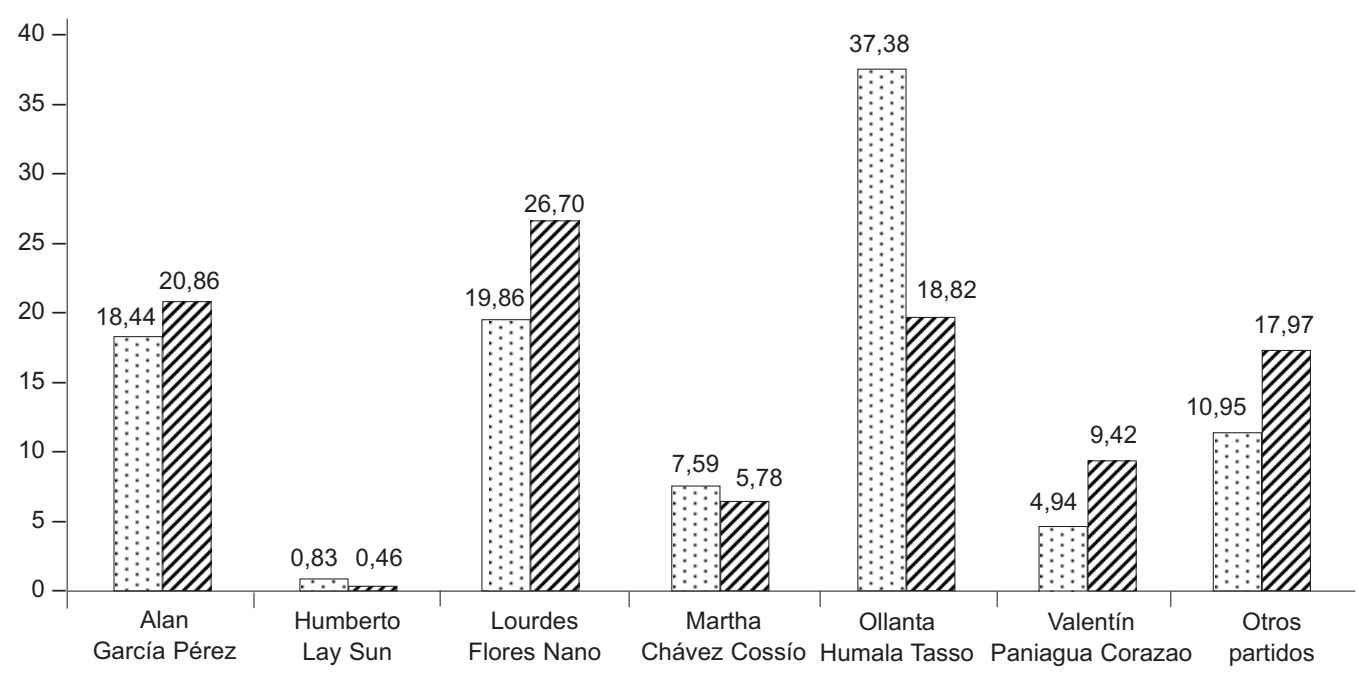

:-: Candidato actor (menciones) $\quad \mathbb{Z}$ Candidato fuente (citas)

Fuente: Base de datos del monitoreo de medios de la Asociación Civil Transparencia.

Elaboración propia. 


\section{La cobertura mediática y la evolución de la intención de voto}

Los medios de comunicación informan y pretenden influir sobre los electores-consumidores, pero, a su vez, son impactados por los resultados de las encuestas, que reflejan las cambiantes opiniones de los votantes, y en menor medida por los reajustes de las estrategias de los candidatos.

Si se observa cómo evolucionó la cobertura periodística durante los últimos tres meses de la campaña, se distinguen algunas constantes: la cobertura dedicada a Ollanta Humala y Alan García tendió a crecer; la de Lourdes Flores se mantuvo constante o declinó; y, salvo en la radio, la de Valentín Paniagua sufrió una pronunciada y creciente disminución.

En la prensa escrita, la cobertura destinada a Humala aumentó en medida muy importante los dos meses previos a las elecciones; las de Lourdes Flores y Alan García sufrieron una ligera disminución, igual que las de Valentín Paniagua y Martha Chávez. En la televisión, los tres principales candidatos merecieron una cobertura creciente; empero, García fue de lejos el que recibió más atención. En la radio, por último, la cobertura se mantuvo constante, aunque la de García subió ligeramente; la de Valentín Paniagua también tuvo un leve ascenso, mientras que, como en la prensa escrita y en la televisión, el espacio que se dedicó a Martha Chávez disminuyó (véase el gráfico 5).
Si se compara esta tendencia de la cobertura con la intención de voto de los principales candidatos recogida por las encuestadoras en el mismo periodo (enero-abril del 2006), se percibe un importante desarrollo paralelo. Ollanta Humala tendió a crecer en las encuestas, aunque su mayor alza ocurrió entre octubre del 2005 y enero del 2006; después de enero se mantuvo relativamente estable.

Mientras tanto, Alan García creció a ritmo muy gradual, pero lo suficiente para desplazar a Lourdes Flores del segundo lugar. La candidata de Unidad Nacional se había mantenido primera en las encuestas aplicadas el 2005; sin embargo, en la mayoría de las del 2006 sufrió un descenso creciente. En el caso de Valentín Paniagua, la tendencia de las encuestas es clara: un descenso permanente y constante (véase el gráfico 6).

$\mathrm{Al}$ respecto se podrían esbozar dos hipótesis: a) que la coincidencia entre la evolución del volumen de la cobertura y la de la intención de voto se origina en el tratamiento - favorable o negativo- de los medios de comunicación a uno u otro candidato; y b) que las encuestas marcan la línea que los medios siguen en cuanto al volumen global de la cobertura, sea porque el candidato se convierte en un personaje "más vendedor" o "menos atractivo" para el elector-consumidor e incluso para el propio medio. 


\section{Gráfico 5}

Evolución de la cobertura mediática

Prensa escrita

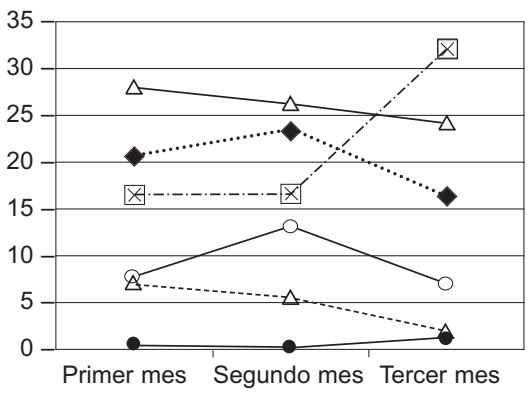

Radio

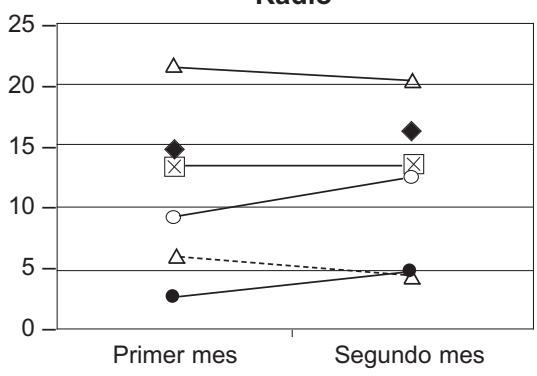

Televisión

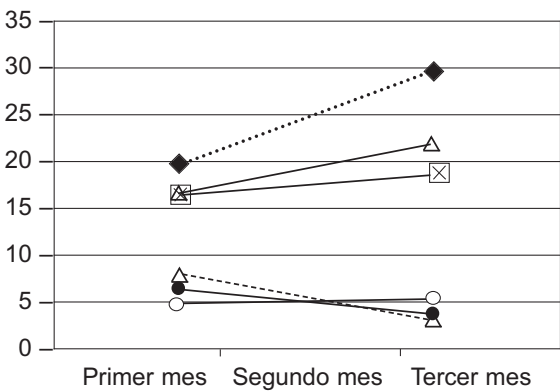

Fuente: Base de datos del monitoreo de medios de la Asociación Civil Transparencia. Elaboración propia.

\section{Gráfico 6}

Evolución de la intención de voto presidencial porcentaje de votos válidos

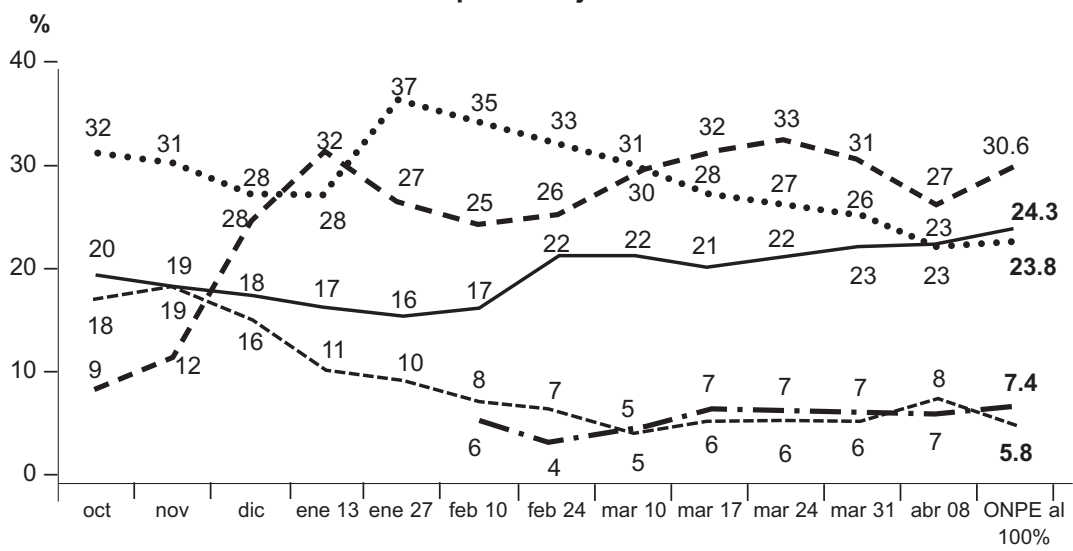

- Ollanta Humala _ Alan García ..... Lourdes Flores - - Martha Chávez - - - Valentín Paniagua

Fuente: Página electrónica de Apoyo Opinión y Mercado. 


\section{El perfil de los candidatos dibujado por los medios}

Para compendiar la información que permite identificar este perfil - siempre sobre la base de la medición de Transparencia- se ha separado, como en los casos anteriores, la cobertura dedicada a los "sucesos de campaña" y la consagrada a los "planes de gobierno".

La cobertura de los "sucesos de campaña" por candidato 5

Las opiniones de Alan García sobre los otros aspirantes a la Presidencia de la República constituyen el rubro que más espacio o tiempo ocupó del total dedicado a este candidato. Esto se reitera en los tres tipos de medios: prensa escrita $(41,75 \%)$, televisión $(34,47 \%)$ y radio $(33,93 \%)$. La cobertura mediática presentó a un Alan García que opinó permanentemente sobre sus adversarios electorales. Debido a las particularidades de la campaña, tuvo que responder a muy escasas denuncias en su contra, y esto se reflejó en lo publicado o difundido.

La cobertura sobre Lourdes Flores también puso énfasis en recoger sus opiniones sobre los otros candidatos. El perfil es, en este sentido, muy semejante al de García: 37,74\% en la prensa escrita, $26,10 \%$ en la televisión y $41,04 \%$ en los programas radiales. En este ámbito, si se comparan las coberturas de García y Flores con el perfil que se dibujó de Ollanta Humala, las diferencias resultan evidentes (véase el gráfico 7a).

En el rubro de "denuncias", esta diferencia se ahonda: mientras que Lourdes Flores y Alan García no tuvieron prácticamente ninguna cobertura referida a este tema como directos implicados, a Ollanta Humala le dedicaron porcentajes importantes: cerca del $18 \%$ en la prensa escrita, cerca del $10 \%$ en la televisión y algo más del $10 \%$ en la radio (véase el gráfico $7 \mathrm{~b}$ ).

En correspondencia con lo anotado, un espacio (o tiempo) significativo de cobertura dedicado a Ollanta Humala se relacionó directamente con su defensa ante las acusaciones y denuncias en su contra. Más de $25 \%$ de la cobertura televisiva de este candidato tuvo que ver con sus respuestas a tales acusaciones; en la prensa escrita alcanzó cerca del 20\%; y en la radio, algo más del 13\% (véase el gráfico 7c).

De la comparación de los perfiles de la cobertura dedicada a los tres principales candidatos, se colige que Lourdes Flores y Alan García tuvieron una mayor "libertad de movimiento", mientras que Humala estuvo más forzado a responder a las denuncias, o por lo menos a comentarlas.

5 Véase la nota 4 para recordar el contenido de esta categoría. 


\section{Gráfico 7a}

Cobertura: Los candidatos opinan sobre los candidatos (porcentajes)

Prensa escrita

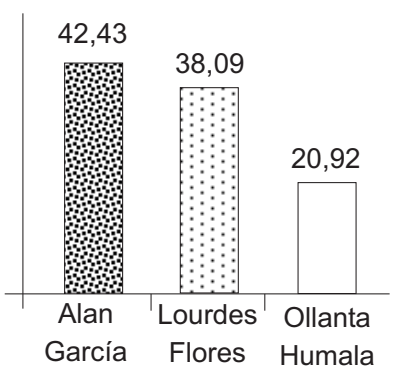

Televisión

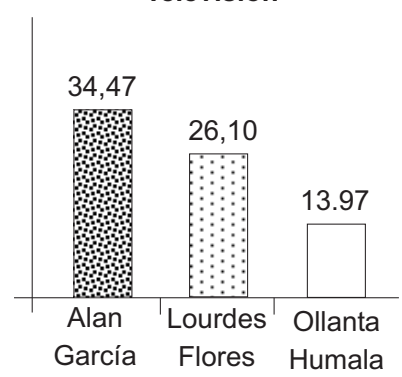

Radio

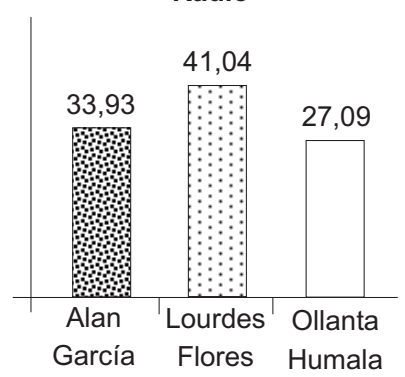

\section{Gráfico $7 b$}

Cobertura: Los candidatos son denunciados (porcentajes)
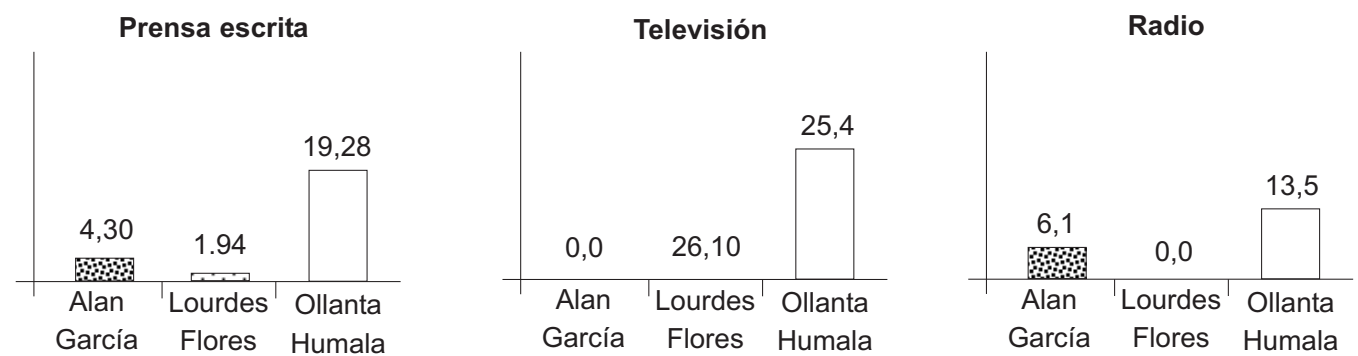

\section{Gráfico 7c}

Los candidatos se defienden de las acusaciones y denuncias (porcentajes)

Prensa escrita

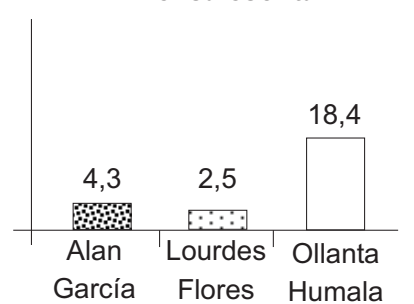

Televisión

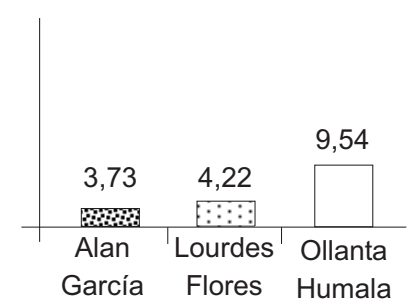

Radio

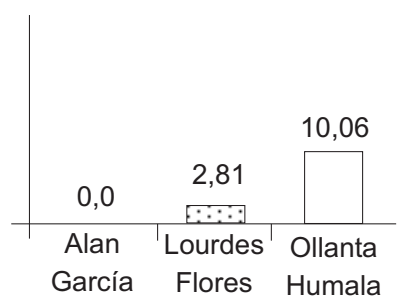

Fuente: Base de datos del monitoreo de medios de la Asociación Civil Transparencia.

Elaboración propia. 
La cobertura de los "planes de gobierno" por candidato ${ }^{6}$

Si se toma como referencia lo difundido en los medios escritos, Alan García concentró su discurso en los derechos sociales y laborales, en la democracia y el Estado de derecho, y en los sueldos estatales. En la televisión, la cobertura del candidato aprista tomó en cuenta sus propuestas sobre las pequeñas y medianas empresas, el desarrollo sostenible y el desarrollo rural; mientras que la radio cubrió sus planes referidos a los derechos laborales, los servicios básicos y el desarrollo rural. En general, el candidato García puso especial énfasis - de acuerdo con la cobertura mediática - en los derechos de las personas (véase el cuadro 1a).
De acuerdo con lo aparecido en los medios escritos, Lourdes Flores, calificada insistentemente como candidata de la derecha por los otros dos principales candidatos, le dio particular importancia a aspectos de su plan de gobierno que debían servirle para cambiar o por lo menos neutralizar esa imagen. Es coherente con esta preocupación su énfasis en asuntos vinculados a la pobreza ciudadana y al desarrollo rural. La televisión dio espacio a sus propuestas sobre pequeñas y medianas empresas, derechos laborales y pobreza; mientras que la radio acentuó la cobertura sobre sus propuestas referidas a la educación, las pequeñas y medianas empresas, los derechos laborales y la pobreza en general (véase el cuadro $1 b$ ).

Cuadro 1a

Alan García Pérez: Temas de su plan de gobierno más mencionados*

\begin{tabular}{lccc}
\hline & Prensa escrita & Televisión & Radio \\
\hline Democracia y Estado de derecho & $\mathrm{X}$ & $\mathrm{X}$ & $\mathrm{X}$ \\
Sueldos estatales & $\mathrm{X}$ & $\mathrm{X}$ & $\mathrm{X}$ \\
Derechos sociales y reproductivos & $\mathrm{X}$ & & $\mathrm{X}$ \\
Derechos laborales & $\mathrm{X}$ & $\mathrm{X}$ & $\mathrm{X}$ \\
Pymes & $\mathrm{X}$ & $\mathrm{X}$ & \\
Desarrollo rural & & $\mathrm{X}$ & $\mathrm{X}$ \\
Desarrollo sostenible & & $\mathrm{X}$ & \\
Jubilación & & & \\
Servicios básicos & $\mathrm{X}$ & & \\
Inversión extranjera & & & \\
\hline
\end{tabular}

* Se consignan los seis temas más recogidos en cada tipo de medio. El orden en el que se presentan toma como base la coincidencia de los temas en los tres tipos de medio.

Fuente: Base de datos del monitoreo de medios de la Asociación Civil Transparencia.

Elaboración propia.

6 Véase la nota 4 para recordar el contenido de esta categoría. 
En relación con Ollanta Humala, la prensa escrita cubrió sus opiniones más que nada sobre política exterior, educación e inversión extranjera. La televisión difundió también de manera preferente sus opiniones sobre política exterior, y a continuación sobre educación e inversión extranjera. La radio puso énfasis en las propuestas del candidato nacionalista sobre democracia y Estado de derecho, y en las referidas a la inversión extranjera. En general, pues, los dos grandes temas de la cobertura dedicada a Ollanta Humala fueron la política exterior y la inversión extranjera, temas que se convirtieron en dos de los más polémicos de la campaña electoral, a partir de asuntos más coyunturales, como el tratamiento del capital chileno y la relación con el presidente de Venezuela, Hugo Chávez (véase el cuadro 1c).

\section{Cuadro 1b}

Lourdes Flores Nano: Temas de su plan de gobierno más mencionados*

\begin{tabular}{lccc}
\hline & Prensa escrita & Televisión & Radio \\
\hline Pobreza & $\mathrm{X}$ & $\mathrm{X}$ & $\mathrm{X}$ \\
Desarrollo rural & $\mathrm{X}$ & $\mathrm{X}$ & $\mathrm{X}$ \\
Política exterior & $\mathrm{X}$ & $\mathrm{XX}$ & $\mathrm{X}$ \\
Pymes & & $\mathrm{X}$ & $\mathrm{X}$ \\
Derechos laborales & $\mathrm{X}$ & & \\
Seguridad ciudadana & $\mathrm{X}$ & & \\
Reforma judicial & $\mathrm{X}$ & $\mathrm{X}$ & \\
Democracia y Estado de derecho & & $\mathrm{X}$ & \\
Inversión extranjera & & & $\mathrm{X}$ \\
Tratado de Libre Comercio & & & \\
Planes (general) & &
\end{tabular}

\section{Cuadro 1c}

Ollanta Humala: Temas de su plan de gobierno más mencionados*

\begin{tabular}{lccc}
\hline & Prensa escrita & Televisión & Radio \\
\hline Democracia y Estado de derecho & $\mathrm{X}$ & $\mathrm{X}$ & $\mathrm{X}$ \\
Recaudación & $\mathrm{X}$ & $\mathrm{X}$ & $\mathrm{X}$ \\
Desarrollo rural & $\mathrm{X}$ & $\mathrm{X}$ & $\mathrm{X}$ \\
Política exterior & $\mathrm{X}$ & $\mathrm{X}$ & \\
Educación & & $\mathrm{XX}$ & $\mathrm{X}$ \\
Inversión extranjera & & $\mathrm{X}$ & $\mathrm{X}$ \\
Tratado de Libre Comercio & $\mathrm{X}$ & \\
Planes (general) & $\mathrm{X}$ & & \\
Lucha anticorrupción & & & \\
\hline
\end{tabular}

* Se consignan los seis temas más recogidos en cada tipo de medio. El orden en el que se presentan toma como base la coincidencia de los temas en los tres tipos de medio.

Fuente: Base de datos del monitoreo de medios de la Asociación Civil Transparencia.

Elaboración propia. 


\section{La ubicación político-mediática de los principales candidatos}

Tomando en cuenta la cobertura dedicada a los tres principales candidatos presidenciales de las elecciones generales del 2006, en esta sección se han organizado sus declaraciones por ejes temáticos para tratar de determinar en qué espacio político resultaron ubicados por los medios, en coincidencia o no con las reales posiciones políticas de estos.

Para trazar las coordenadas hemos considerado en primer lugar dos grandes ejes temáticos de referencia: el político y el económico; a cada uno, a su vez, se le ha asignado dos ejes centrales y dos intermedios.

En el plano político los ejes centrales, alternativos y formalmente polares son: "Democracia e institucionalidad democrática" y "Autoritarismo". Los ejes intermedios, que permiten efectuar un acercamiento más preciso, son el fortalecimiento de los "Derechos individuales" y la prevalencia del "Orden", el primero en el ámbito de la democracia y el segundo como una variante menos radical que el autoritarismo.

\begin{tabular}{cccc}
\hline $\mid$ & $\mid$ & $\mid$ & Autoritarismo \\
$\begin{array}{c}\text { Democracia e } \\
\text { institucionalidad } \\
\text { democrática }\end{array}$ & $\begin{array}{c}\text { Derechos } \\
\text { individuales }\end{array}$ & Orden &
\end{tabular}

En el plano económico, es decir, en relación con las propuestas vinculadas a la economía, los dos ejes polares son el fortalecimiento del "Libre mercado" y el fortalecimiento del papel del Estado en la economía ("Estatis$\mathrm{mo}^{\prime \prime}$, entendido como la preeminencia del Estado en la economía). El eje intermedio, "Mercado regulado", agrupa las propuestas o iniciativas que, estando en el espacio del mercado, reconocen la necesidad de aplicar políticas gubernamentales de regulación; mientras que el eje secundario, "Estado promotor", se distingue del "Estatismo" porque acepta que en el área donde se plantea una determinada iniciativa estatal participen de manera simultánea la iniciativa y la propiedad privadas. ${ }^{7}$

7 La ubicación de los temas, de acuerdo con los ejes presentados, contiene una inevitable arbitrariedad, que el autor asume como riesgo. 
Ámbito temático político

Prensa escrita

En este ámbito, los medios de prensa escritos recogieron en especial la insistencia de Alan García en el eje secundario "Derechos individuales"; entre otros, los derechos laborales. Lourdes Flores fue presentada sobre todo como ligada al eje secundario "Orden". El discurso de Ollanta Humala fue vinculado por la prensa escrita tanto a uno como a otro eje ("Orden" y "Derechos individuales"), pero en menor medida que los otros dos candidatos.

El segundo eje más tomado en cuenta en relación con Alan García es el eje secundario "Orden"; en el caso de Lourdes Flores, este segundo resulta ser el eje polar "Institucionalidad democrática".

Así pues, al margen de la particularidad de cada discurso político y de los énfasis y las iniciativas distintas vinculadas a los derechos individuales, en lo recogido por la prensa escrita estuvo siempre muy presente el eje “Orden” (ver el gráfico 8a).

\section{Gráfico 8 \\ Ámbito temático político: ubicación del discurso según lo recogido por los medios (porcentaje de la cobertura total por tema)}

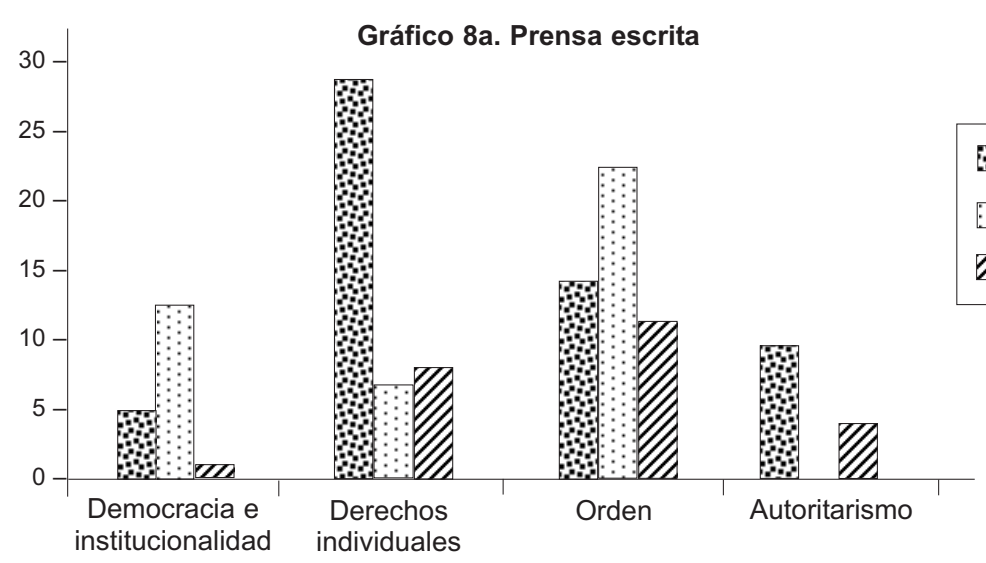

Fuente: Base de datos del monitoreo de medios de la Asociación Civil Transparencia. Elaboración propia. 


\section{Gráfico 8}

Ámbito temático político: ubicación del discurso según lo recogido por los medios (porcentaje de la cobertura total por tema)

\section{Gráfico 8b. Televisión}

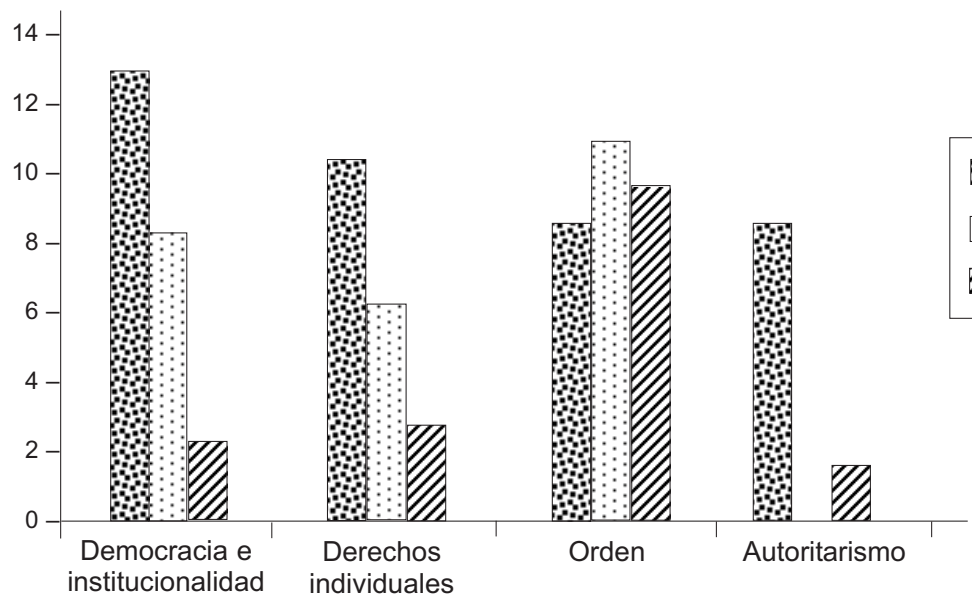

Fuente: Base de datos del monitoreo de medios de la Asociación Civil Transparencia. Elaboración propia.

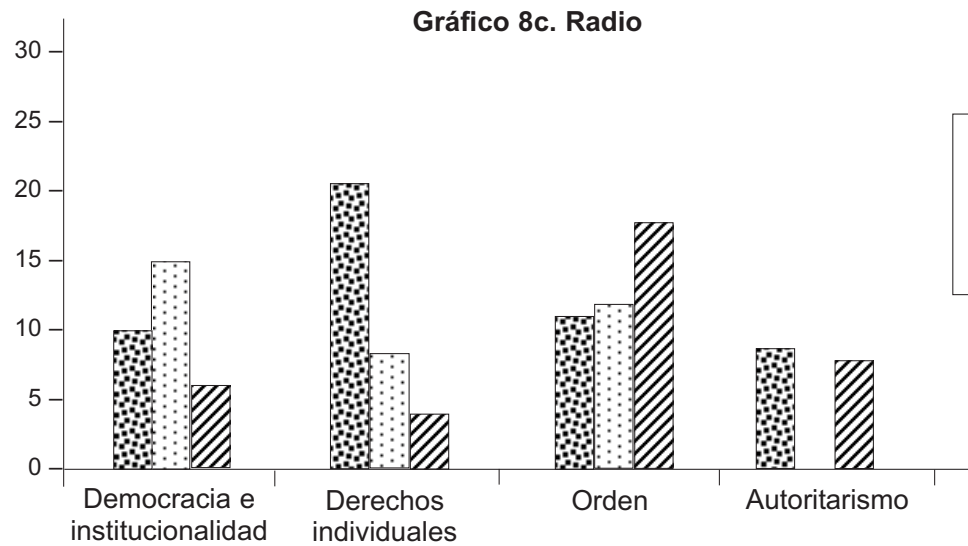

Fuente: Base de datos del monitoreo de medios de la Asociación Civil Transparencia. Elaboración propia. 
Televisión

La televisión mostró sobre todo un Alan García preocupado por lo que se dispondría en los ejes "Democracia" y "Derechos individuales". Hay una variación, si se compara con la prensa escrita, pero se mantiene la fuerte mención a la defensa de los derechos individuales.

Lourdes Flores es presentada, igual que por la prensa escrita, como más interesada en el eje "Orden" y, en menor grado, en el eje "Democracia e institucionalidad democrática"; por ello, es comprensible que este discurso apareciera como más conservador para los electores. A Ollanta Humala también se le mostró como un postulante muy preocupado por el orden, en coincidencia con la percepción de los votantes, según todas las encuestas de esos meses (véase el gráfico $8 b$ ).

\section{Radio}

El monitoreo en radio muestra que este medio ratifica la insistencia del candidato del Apra en el eje "Derechos individuales", presentado como aspecto medular de su discurso; la democracia y el orden son ubicados en un claro segundo plano. Sin embargo, en la disputa con Ollanta Humala, Alan García también lanzó propuestas como la pena de muerte y la posible clausura constitucional del Congreso, de corte autoritario.
Lourdes Flores es presentada como una candidata preocupada sobre todo por temas concernientes al eje "Orden" y al eje "Democracia e institucionalidad democrática". Ollanta Humala adquiere más un perfil preocupado por propuestas relacionadas con los ejes "Orden" y "Autoritarismo" (véase el gráfico 8c).

Ámbito temático económico

Prensa escrita

En relación con las propuestas económicas, lo más saltante es el énfasis puesto por Humala - de acuerdo con lo recogido por los medios de comunicación - en la urgencia de una política de consolidación del Estado. El discurso de Humala apareció vinculado a una propuesta nacionalista, a la recuperación del papel del Estado en la economía y a las llamadas empresas estratégicas. En el esquema planteado, todo esto se ubicaría en un ámbito cercano al eje polar "Estatismo".

Según lo recogido por la prensa escrita, Lourdes Flores y Alan García pusieron énfasis sobre todo en propuestas vinculadas con el eje secundario "Estado promotor": programas relacionados con la política de créditos y con el sector agrario y laboral.

De acuerdo con lo observado, el discurso de Ollanta Humala reivindicando el papel del Estado tuvo un 
fuerte impacto en la campaña y alentó a que sus dos principales adversarios pusieran énfasis - de diversa índole- en el papel que el Estado debe cumplir en el desarrollo social y productivo, cercano al eje "Estado promotor" (véase el gráfico 9a).

\section{Televisión}

La cobertura periodística en televisión mostró una mayor incidencia de $\mathrm{Hu}$ mala en el nuevo y más importante papel que cabría al Estado en caso de ser elegido primer mandatario del país, énfasis cercano al eje "Estatismo". Si se compara este tipo de informaciones o comentarios con los otros ejes temático-económicos, las propuestas cercanas a los ejes "Libre mercado" y "Mercado regulado" prácticamente no existieron (o por lo menos no fueron tomadas en cuenta por los medios, lo que de todos modos mostraría su poca incidencia en el discurso global de este candidato).

Lourdes Flores y Alan García, igual que en la prensa escrita, son presentados como preocupados principalmente por la constitución de un Estado promotor o social. De acuerdo con lo recogido, Lourdes Flores puso énfasis particular en propuestas vinculadas con la educación y la salud, mientras que Alan García lo hizo en las relacionadas con la agricultura y la democratización de las políticas de crédito; es decir, sus discursos resultan ubicados en el eje "Estado promotor" (véase el gráfico 9b).

\section{Radio}

En relación con la política económica, la pauta informativa de la radio tiene grandes semejanzas con la de la televisión y la prensa escrita. Ollanta Humala fue presentado como un candidato preocupado por la consolidación del Estado interventor y del Estado promotor. Sus propuestas en un número superior se preocuparon otra vez en este espacio por insistir en la urgencia de un Estado que tenga una mayor injerencia en la economía. Si se observa el gráfico $9 \mathrm{c}$, se concluye que las propuestas relacionadas con el Estado absorbieron prácticamente el conjunto del discurso humalista relacionado con la economía.

Lourdes Flores y Alan García, como en los otros medios, fueron presentados sobre todo preocupados por el Estado promotor. Si se trata de hacer una distinción, en el caso de Lourdes Flores el énfasis está puesto en el Estado social (educación, salud y otros), y en el de Alan García en el Estado promotor (programas de desarrollo de la sierra y de beneficio a los pequeños y medianos promotores urbanos) (véase el gráfico 9c). 


\section{Gráfico 9}

Ámbito temático económico: ubicación del discurso según lo recogido por los medios (porcentaje de la cobertura total por tema)
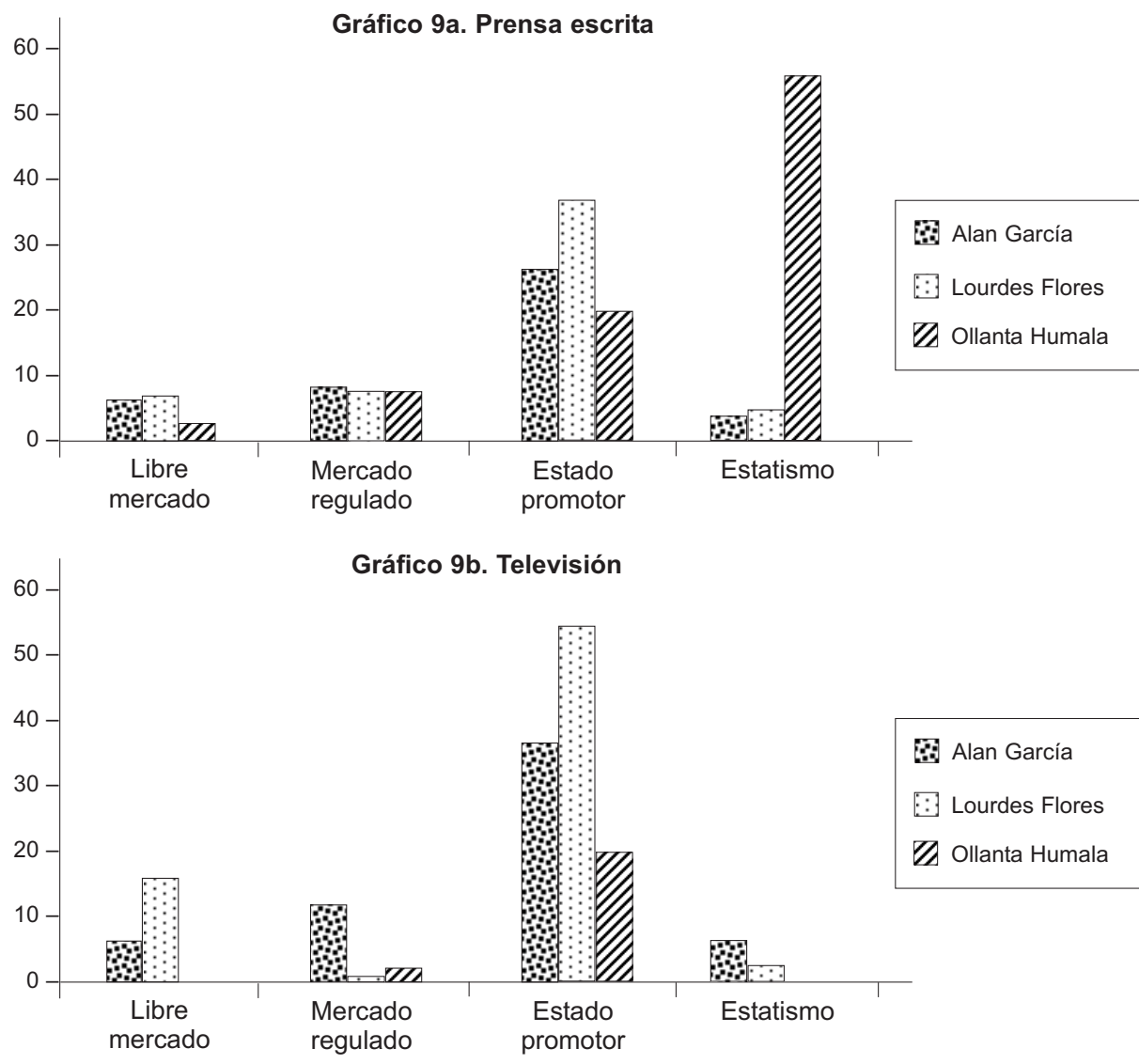

Alan García

$\therefore:$ Lourdes Flores

$\square$ Ollanta Humala

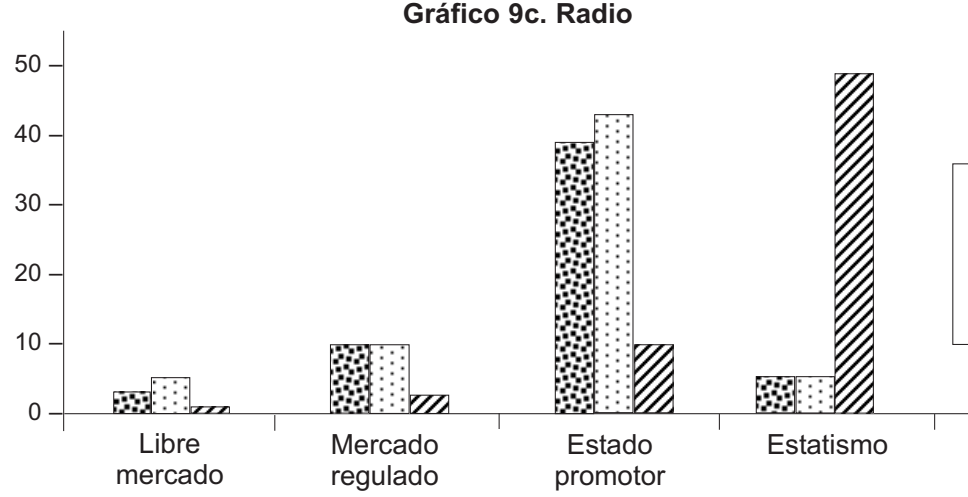

Fuente: Base de datos del monitoreo de medios de la Asociación Civil Transparencia.

Elaboración propia. 
Estrategias de campaña y ubicación político-mediática

Si se observa la cobertura de los medios sobre los principales candidatos, se constata que las iniciativas vinculadas al eje "Libre mercado" y "Mercado regulado" fueron muy escasas, a diferencia de lo que pudo haber sido hace diez o quince años, cuando se inició e implementó el proceso de privatización del Estado.

La campaña mediática se desplazó hacia el papel del Estado, el orden (es recurrente, por ejemplo, la preocupación por una mayor seguridad ciudadana) y la recuperación y consolidación de los derechos individuales. En la prensa, estos son los tres grandes temas del lapso analizado, lo que permite considerar que la campaña se situó en el centro o, más precisamente, en un espectro centroizquierdista, posición bastante distinta de la que expresan en tiempos "normales" la mayoría de los medios de comunicación y los partidos políticos de más añosa fundación, incluidos el Apra y Unidad Nacional.

Queda claro que, por lo menos de acuerdo con lo informado, Alan García hizo esfuerzos para ser percibido por la población como un candidato que al alcanzar la presidencia se preocuparía por mejorar la calidad de vida de las personas y por superar la deteriorada situación en la que se encuentra el Estado peruano desde hace aproximadamente dos décadas.
Al mismo tiempo, a diferencia de Ollanta Humala, evitó convertir sus propuestas sobre el fortalecimiento del Estado en el centro de su campaña electoral.

Siempre de acuerdo con lo reflejado en los medios, Lourdes Flores, identificada por los otros candidatos presidenciales y por importantes sectores de la opinión pública como una representante de la derecha política nacional, intentó neutralizar esta imagen poniendo énfasis en el papel que cumpliría el Estado, de ser ella presidenta, en garantizar la educación y la salud, y también subrayó su interés por consolidar el papel promotor del Estado. Si se suman sus propuestas recogidas en torno al "fortalecimiento del Estado" y al "Estado promotor", estas superan largamente las del propio Alan García, percibido durante la campaña como "el candidato de centro".

Lourdes Flores se cuidó de diferenciarse de sus principales opositores, que deslizaron iniciativas que corresponderían a los ejes polares del esquema de análisis planteado: en el plano político, García propuso, por ejemplo, la incorporación de la pena de muerte para violadores de niños y la posibilidad de clausurar el Congreso si su accionar llegaba a ser considerado deficiente, acciones que cabrían en el eje "Autoritarismo". En el plano económico, Ollanta Humala aparece como el que más insiste en el fortalecimiento del papel del Estado como propietario de medios de producción, 
y -en concordancia con esta preocupación- propuso la reforma de la Constitución vigente, calificada de neoliberal, en aras de recuperar el rol que la de 1979 le confería al Estado, acciones posibles de ubicar en el eje polar "Estatismo".

Humala planteó igualmente una política más agresiva del Estado en el control de los puertos y en la exploración y explotación de petróleo. Sin embargo, en el ámbito político se cuidó de hacer propuestas que lo vincularan con el autoritarismo (aunque las críticas contra él tenían ese énfasis). Por el contrario, criticó a Alan García por su propuesta de cerrar eventualmente el Congreso - hay que aclarar que la actual Constitución lo permite bajo determinadas condiciones - y no se sumó a la propuesta de pena de muerte.
Los medios, los candidatos y los electores en campaña: Entre fidelidades y amotinamientos ${ }^{8}$

\section{La agenda mediática y la administración periodística de los temas relevantes durante la campaña electoral}

En esta segunda parte se pretende observar el proceso y las características de la puesta en escena de los temas de discusión; es decir, el establecimiento de la agenda durante la campaña electoral.

En relación con la agenda mediática, esta tiene un punto de quiebre en enero del 2006, a inicios del tramo final de la primera vuelta, cuando el candidato del nacionalismo, Ollanta Humala, apareció primero en las encuestas de intención de voto. Es recién

8 En el contexto de la presentación de la hipótesis de la agenda setting, el italiano Mauro Wolf recoge de McLeod-Becker-Byrnes (1974) tres tipos de agenda del público:

“Pueden distinguirse tres tipos de agenda del público o, como afirman McLeod-BeckerByrnes (1974), tres tipos de relevancia:

a) La agenda intrapersonal (o relevancia individual), que corresponde a lo que el individuo considera que son los temas más importantes: es una relevancia personal asignada a un problema de la persona, en los términos del propio conjunto de prioridades;

b) La agenda interpersonal (o relevancia comunitaria), es decir, los temas de y sobre los que el individuo habla y discute con los demás: define por tanto una relevancia intersubjetiva, es decir, la actual cantidad de importancia asignada a un tema en una red de relaciones y comunicaciones interpersonales.

c) El tercer tipo de agenda corresponde a la percepción que tiene un sujeto del estado de la opinión pública [...]: es la relevancia percibida, es decir, la importancia que el individuo cree que los demás atribuyen al tema; correspondiente a un "clima de opinión" y puede incluirse en las llamadas tematizaciones". (WOLF, Mauro. La investigación de la comunicación de masas, 1996, pp. 196-197). 
en ese momento cuando se introducen en la agenda electoral aspectos vinculados a la desigualdad social y a los cuestionamientos del programa económico vigente. Saltan igualmente al primer plano demandas y debates referidos a una mayor presencia del Estado - "nacionalista", "promotor" o "social" - y a un contenido nacionalista de determinadas políticas públicas, sobre todo en relación con Chile y Estados Unidos.

Entre enero y febrero del 2006, los medios recogieron la tendencia a la polarización entre la centroderecha y el nacionalismo radical, personificados en la confrontación entre Ollanta Humala y Lourdes Flores. Posteriormente, y de manera muy gradual, Alan García consiguió debilitar esa polarización al constituir un espacio más de centro. Las encuestas grafican este proceso y los medios de comunicación fueron sensibles a estos cambios, que determinaron una modificación definitoria en el diseño de la agenda mediática. ${ }^{9}$

Durante el periodo analizado, los medios de comunicación se desenvolvieron como actores políticos: tuvieron una conducta activa y mucha iniciativa. Hubo casos en los que los consumidores-electores los vieron como parte de la publicidad o del márketing político de algún candidato. Si se trata de trazar una alineación mediática, habría que decir que esta se armó sobre todo por negación: cómo se impedía el triunfo del nuevo outsider o marginal - esta vez, nacionalista - de la política peruana: Ollanta Humala.

Es más difícil precisar qué candidato presidencial tuvo el apoyo más decidido de los medios en este último trecho de la primera vuelta. No obstante, algunas encuestas aplicadas en este lapso y el propio monitoreo de la cobertura mediática indican que habría sido Lourdes Flores (Unidad Nacional). Según la encuesta de la Universidad de Lima aplicada en mayo del 2006 (después de la primera vuelta) en Lima metropolitana y el Callao, ante la pregunta “ ¿Y con qué candidato se parcializaron los medios?", el 57,4\% respondió que con Lourdes Flores; el 27\%, con Alan García; y el 11,7\%, con Ollanta Humala. Sin embargo, ante la interrogante “¿Considera que el apoyo de los medios de comunicación favoreció o perjudicó a ese candidato?", cerca del $57 \%$ de las personas encuestadas contestó que no y 40\% que sí. Resulta significativo que entre los sectores $\mathrm{A}$ y $\mathrm{B}$ de Lima, en los que se concentró el voto por Lourdes Flores, más del 73\% consideró que el apoyo fue perjudicial.

9 Hasta diciembre del 2005, la ubicación de Lourdes Flores en el primer lugar de las encuestas permitió que la agenda electoral tuviera un contenido continuista y de alguna manera inercial, en relación con los cinco años de la presidencia de Alejandro Toledo. 
La agenda electoral del periodo comentado (primera vuelta de las elecciones del 2006) fue producto de una simbiosis mediática entre: a) los ángulos informativos y las líneas editoriales de los medios de comunicación; b) el electorado; y c) los intereses de los candidatos.

La definición de la agenda fue un proceso activo, de ida y vuelta: así, la capacidad de impacto y sostenibilidad temporal de unas informaciones en detrimento de otras estuvo basada en su validación o jerarquización, según la relevancia que determinó el electorado y bajo ciertos climas de opinión, y el impacto de las estrategias de los candidatos. Esta aceptación o rechazo de las noticias fue tomada en cuenta por los medios (feed back) para reiterar o difundir notas similares y establecer nuevas agendas. Así, podemos enumerar ciertos temas que desempeñaron un papel importante para los medios y que fueron producto de este juego entre los tres actores principales del proceso:

- La relación entre el presidente de Venezuela, Hugo Chávez, y el candidato Ollanta Humala.

- La intromisión del presidente de Venezuela, Hugo Chávez, en el proceso electoral peruano.

- Lourdes Flores, la derecha y los ricos.

- El antichilenismo de Humala, que llevó también a tratar temas de polí- tica exterior en relación con Bolivia, Venezuela y Estados Unidos.

- Las empresas mineras: revisión de contratos y regalías.

- El Tratado de Libre Comercio con Estados Unidos.

- Ollanta Humala frente a los campesinos cocaleros.

- El caso Madre Mía y las presuntas violaciones de los derechos humanos por parte de Ollanta Humala.

- El primer gobierno de Alan García.

- Los conflictos dentro de las alianzas Unión por el Perú-Partido Nacionalista y Unidad Nacional.

\section{Los candidatos y sus estrategias de proyección mediática}

La imagen mediática de los candidatos no solo dependió de los medios de comunicación sino también del perfil que construyeron ellos de sí mismos. Cabe descifrar, entonces, en qué medida el candidato se estableció a sí mismo como un personaje noticioso y cuánto el medio convirtió al actor en un personaje noticioso.

En el periodo analizado se distinguieron tres tipos de candidatos de peso para los medios y el electorado: a) los que poseyeron un "perfil propio", cuyos elementos fueron la base para que los medios construyeran su imagen mediática (Alan García, Ollanta 
Humala y Martha Chávez); b) los que trabajaron a partir de su perfil principalmente mediático, es decir, que basaron su popularidad, aceptación y estrategias en la imagen que los medios proyectaron sobre él (Lourdes Flores); y c) los que no lograron asentarse en uno ni otro tipo de perfil (Valentín Paniagua).

En el caso de los candidatos consignados en el primer tipo (García, Humala y Martha Chávez, aunque esta en menor medida), los medios tomaron ciertas características del perfil que ellos se construyeron y las proyectaron hacia la opinión pública según la línea editorial o periodística y envueltas en temas que consideraron de relevancia política o coyuntural, como los párrafos antes citados.

Sin dejar de lado que García es un candidato más experimentado y mediático que Humala, que no tiene un gran dominio escénico y fue un tanto esquivo con los medios, ambos mantuvieron un perfil propio muy fuerte, sustentado por sólidos grupos electorales que se identificaban con ellos por tradición partidaria o por sus planteamientos "antisistema", y cuyo voto resultó invariable. Por lo tanto, en ambos casos, los medios solo subrayaron o atenuaron las características que consideraban favorables o desfavorables, de acuerdo con sus líneas informativas o editoriales, matizándolas con temas de la coyuntura.

Lourdes Flores, como se ha indicado, corresponde al tipo de candidato que resulta más una construcción del medio. Es decir, no logró perfilarse con sólidas características propias al asumir la campaña, y su perfil político - como también la proyección de su imagen - dependió en gran medida de lo que los medios iban construyendo sobre ella para hacerla noticia. Si bien mantuvo a una porción del electorado convencida de votar a su favor, Lourdes Flores no pudo ir más allá de la imagen que los medios proyectaban de ella, que finalmente la dejó fuera de carrera para la segunda vuelta.

El tercer tipo de candidato - aquel carente de perfil propio y de perfil mediático - pierde toda capacidad práctica de hacer noticia. La campaña carece de atractivos y a su alrededor no hay polarizaciones que llamen la atención del público ni de los medios. Valentín Paniagua, a pesar de su buena imagen ante la opinión pública como persona carismática, honesta y de intachable trayectoria política, no pudo revertir este handicap que lo llevaría a un quinto lugar.

\section{A modo de conclusión: La difícil sintonía entre los medios y los electores}

En la definición del voto del elector influyen los medios y las campañas de los candidatos, pero también $-\mathrm{y}$ a veces de manera decisiva- la desigualdad social, las diferencias culturales, las identidades políticas territoriales, la ideología (incluyendo tradi- 
ciones y trayectorias políticas). El elector tiene su propia agenda. ${ }^{10}$ Existen, además, importantes espacios de intercambio colectivo con injerencia en la construcción del voto, como la familia, el barrio, el lugar de trabajo, la internet, los grupos religiosos, los amigos...

En estos espacios, numerosos peruanos construyen su opinión política - ligada al terreno electoral - al margen de las campañas mediáticas o incluso en oposición a estas. Empero, la relativa autonomía no significa necesariamente que los votantes procesen la decisión en ámbitos o instituciones forjadoras de la democracia, en el sentido institucional del término-como los partidos o los sindicatos-, sino más bien, como se ha señalado, en los espacios identitarios territoriales, corporativos o socioeconómicos. Entre los sectores más adinerados, por ejemplo, solo el 10\% simpatizaba con Humala, y entre los más pobres, el 50\% o 60\%.

Las identidades territoriales tienen también un importante impacto en la creación de empatía con los candida- tos. Si se rastrea el voto por regiones se comprueba que el ámbito territorial-cultural tuvo más influencia que la situación socioeconómica de los ciudadanos, sin desconocer que en la mayoría de las regiones la pobreza rural está sumamente extendida.

El norte del país, vía el Apra, y la capital de la república, vía partidos de derecha o centroderecha, han tenido una representación política nacional medianamente estable (véase el gráfico 9); esto no ha ocurrido en el centro del país y sobre todo en el sur serrano -Puno, Cusco y Arequipa-. Estas regiones se han visto huérfanas de representación nacional o han tenido una representación permanentemente en crisis o recomposición, ya sea porque la izquierda - que dominó parcialmente este espacio- desapareció del escenario político, porque los caudillos locales tienden a una corta vida electoral, o porque apostaron por marginales (Alberto Fujimori) o políticos que enarbolaban más un gesto radical que una propuesta programática de cambio (Alejandro Toledo).

10 Según Umberto Eco, la visión catastrofista sobre los efectos de la comunicación es sistemáticamente sobredimensionada por quienes ven a los receptores como "masa" (los "apocalípticos"). Sin embargo, "que más tarde dichas masas entren o no en el juego, que en realidad posean un estómago más resistente de lo que sus manipuladores creen, que sean capaces de ejercitar la facultad de discriminación sobre los productos que le son ofrecidos para consumo, que sepan resolver en estímulos positivos, dirigiéndolos a usos imprevistos, mensajes emitidos con intención diversa, es problema de distinta índole". ECO, Umberto. Apocalípticos e integrados, 2004, p. 41. 
Gráfico 10

Resultados de las elecciones presidenciales 1980-2006 (porcentajes)
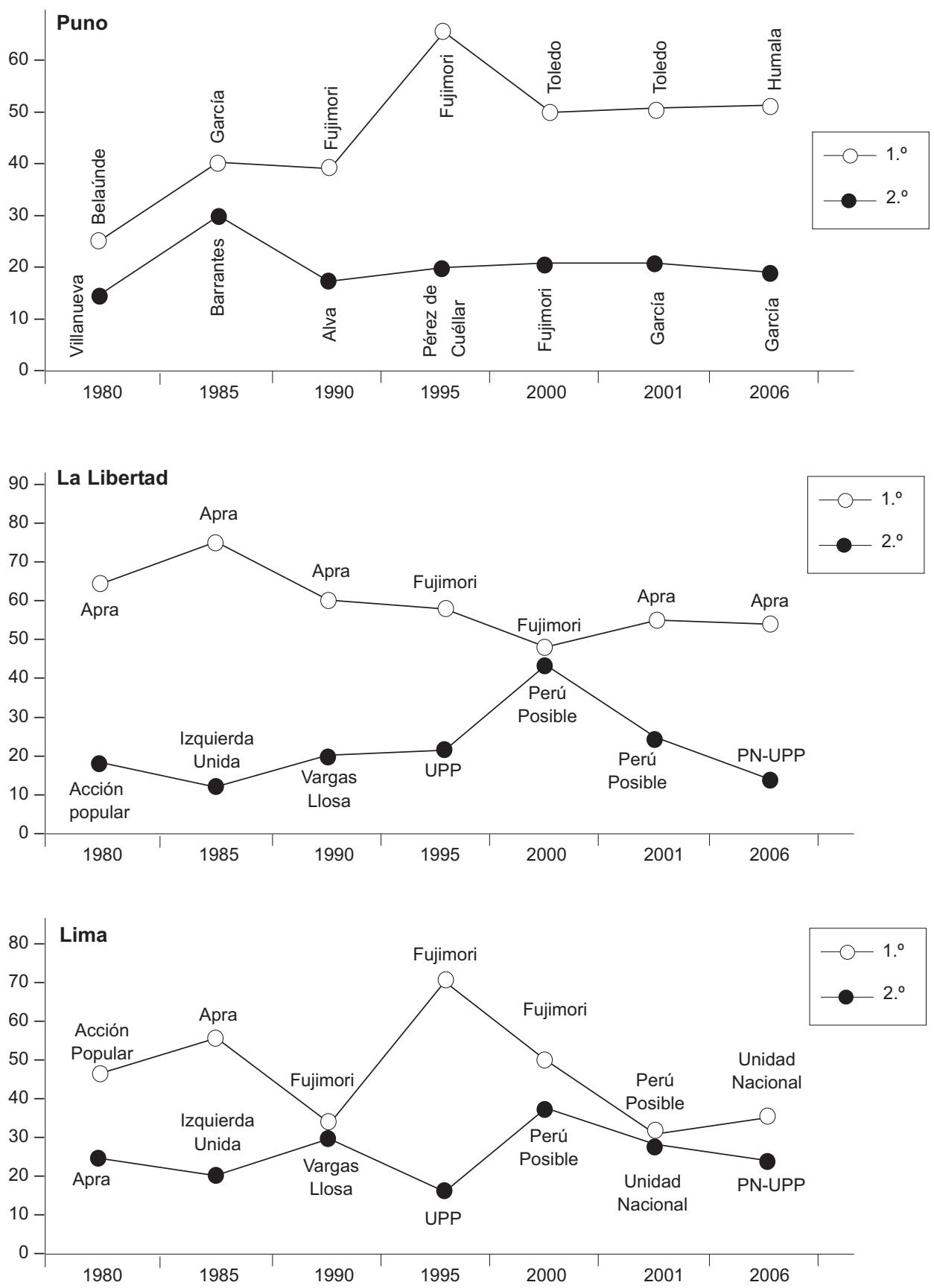
El diferente nivel de desarrollo productivo y de mercado capitalista por regiones, así como la presencia de poblaciones mayoritariamente quechuas o aimaras, o de bolsones de población de selva, condicionaron la votación. Lo mismo se podría decir del electorado de Lima, que en la primera vuelta votó sobre todo por Lourdes Flores y después se convirtió en un factor decisivo para la victoria de Alan García.

Otra razón de la particular conducta de los electores peruanos es el conocido vacío de representación política, especialmente entre los sectores más pobres de la población, al no haber una izquierda medianamente sólida o una derecha popular (salvo el fujimorismo en Lima) que cubra sus expectativas. Sin duda, la historia política de algunas importantes regiones del país debe también ser tomada en cuenta: la costa norte, prioritariamente aprista desde hace cerca de setenta años; un electorado preferentemente de centro o centroderecha en Lima, la capital; y una región central y sobre todo sur muy erráticas en cuanto a identidad política, lo mismo que la Amazonía.

¿Por qué los medios no determinaron los resultados del proceso electoral? Las explicaciones son varias: la falta de confianza estructural de la población en los medios de comunicación (la mencionada encuesta de la Universidad de Lima, aplicada en la capital de la República en mayo del 2006, entre la primera y la segunda vuelta electoral, constató que el 71,6\% de los limeños confía poco $-62,3 \%-$ o nada $-9,3 \%$ - en los medios de comunicación) y la ausencia de sintonía de los mismos medios y del espectro político electoral - parcialmente corregida con la aparición protagónica de Ollanta Humala, a partir de enero del 2006con las preocupaciones o demandas de amplios sectores de la población, vinculadas sobre todo a la política económica y al marginal papel subsidiario que el Estado cumple en el país desde hace más de 15 años.

En síntesis, los medios influyeron en qué y cuánto discutieron los electores sobre determinados temas; y contribuyeron, con los candidatos y los electores, en la construcción y evolución de la agenda electoral. Pero no determinaron los resultados electorales más que la estrategia de cada candidato, las identidades territoriales y corporativas de los electores, el sentido clasista del candidato desde el punto de vista de los votantes, la falta de representación política de regiones enteras y la desconfianza de los peruanos frente a los medios de comunicación. 